\title{
Rice Bran as a Functional Food: An Overview of the Conversion of Rice Bran into a Superfood/Functional Food
}

\author{
Md. Alauddina, Jahidul Islama, Hitoshi Shirakawaa, \\ Takuya Kosekib, Ardiansyahc and Michio Komaia
}

Additional information is available at the end of the chapter

http://dx.doi.org/10.5772/66298

\begin{abstract}
Rice bran is a byproduct of the rice milling process; it constitutes $10 \%$ of rice, with a potential global production of 48 million tons per year. The major portion of this is used as animal feed or discarded as waste material. However, rice bran is attracting attention from researchers because it is widely available, cheap and rich in nutrients such as protein, fat, carbohydrates, bioactive compounds and dietary fiber. Many foodprocessing techniques that have improved rice bran resources have been pioneered, such as enzyme treatment and fermentation. We have been investigating the functional role of rice bran since 2003. Our experiments revealed that rice bran and its active compounds, such as $\gamma$-oryzanol, tocopherol, tocotrienol, adenosine and ferulic acid, play a role as a functional food. In this review, we summarize how rice bran is a super food and functional food to illustrate the global interest in rice bran and its functional aspects and medicinal qualities. We also describe the techniques to prepare functional bran and the composition and health benefits of functional bran, which may encourage entrepreneurs to produce rice bran-based food on a large scale and meet the global demand for super foods and functional foods.
\end{abstract}

Keywords: functional bran, bioactive compounds, adenosine, ferulic acid, $\gamma$-oryzanol

\section{Introduction}

Throughout the history of human civilization, food has been developed to provide nutrition and sustain health. In this regard, the development of "functional foods" is gaining momentum, 
because consumers in developing and developed countries wish to maintain better health [1]. The concept of a "functional food" originated in the 1980s in Japan, from where it migrated to Europe and the United States [2]. In general, a functional food is a modified food that improves health and well-being beyond the effects of the nutrients it contains. Generally, foods can be made functional foods by increasing the concentration of, adding, or improving the bioavailability of particular components. Food is considered functional when it can be established that it enhances body function or reduces the risk of diseases [3].

Functional foods have recently emerged as convenient, inexpensive and promising candidates to prevent chronic health problems. Rice bran, a byproduct of the rice milling process, is derived from the outer layer of the rice grain; it contains a number of nutrients and biologically active compounds. Rice bran is often processed using stabilization, fractionation, enzymatic treatment, or fermentation. This treated rice bran is called functional bran. The identification of the bioactive components contained in rice bran has reinforced its status as a functional food.

Experiments have revealed that enzyme-treated or ethanol-extracted rice bran ( $6 \%$ of the diet for 8 weeks) improves blood pressure (BP), the lipid profile and glucose metabolism. Furthermore, adenosine supplementation (10 mg/kg body weight), an active component of functional bran, improved metabolic syndrome in stroke-prone spontaneously hypertensive rats (SHRSPs) [4]. In addition, ferulic acid (FA) supplementation ( $9.5 \mathrm{mg} / \mathrm{kg}$ body weight), another active compound in functional bran $(0.19 \mathrm{mg} / 100 \mathrm{~g}$ of rice bran), improves BP and the lipid profile [5]. Thus, the aim of this review was to analyze the evidence of rice bran as a functional food as well as the global interest in rice bran.

\section{Compositional distinctiveness of rice bran}

The composition of rice bran differs with the variety of rice, geographical conditions and processing methods. Rice bran, the outer layer of the rice grain, accounts for $8-10 \%$ of the total weight of the grain; however, it contains most of the nutrients: carbohydrates (34-62\%), lipids $(15-20 \%)$, protein (11-15\%), crude fiber (7-11\%) and ash (7-10\%). In particular, rice lipids and bioactive components are concentrated in rice bran [6, 7]. Fatty acids such as palmitate (21$26 \%)$, linoleate (31-33\%) and oleate (37-42\%) are predominant in rice bran. In addition, due to its high content of polyunsaturated fatty acids, rice bran is considered a healthy food $[7,8]$. Significant quantities of bioactive compounds such as $\gamma$-oryzanol, tocotrienol, tocopherol and $\alpha$-sitosterol as well as dietary fibers such as $\alpha$-glucan, pectin and gum have been found in rice bran $[9,10]$. Specifically, $\gamma$-oryzanol, the main antioxidant present in rice bran, has a 10-times higher antioxidant activity than tocopherol, while tocotrienol has 40-60 times greater antioxidant activity than tocopherol. However, the proportions of these phytochemicals vary with the type of rice cultivar [11]. In addition, rice bran contains 4-hydroxy-3-methoxycinnamic acid (FA), which has photoprotective and antioxidative effects [12-14].

The health information website SelfNutritionData (http://nutritiondata.self.com) reports that one cup of crude rice bran provides 88 calories and that $28 \mathrm{~g}$ of rice bran contains $5.8 \mathrm{~g}$ of fat, $1.2 \mathrm{~g}$ of which is saturated and $4.2 \mathrm{~g}$ of healthy unsaturated fatty acids. According to Walter 
Willett, a nutritionist from Harvard University (https://www.hsph.harvard.edu/walterwillett), heart health is directly related to the ratio of unsaturated to saturated fatty acids in the diet. In addition, one cup of rice bran delivers $13.9 \mathrm{~g}$ of carbohydrate and $3.7 \mathrm{~g}$ of protein, which is $7 \%$ of our daily requirement and a single serving of rice bran delivers more than half of our daily nutritional requirements of thiamine, niacin and pyridoxine.

\section{Rice bran as functional bran}

\subsection{Fermentation}

Owing to its disease-preventing properties, rice bran is popular in the food industry. Interestingly, the antidiabetic and antidyslipidemic activities of rice bran have been reported in different animal model experiments [15-17]. Furthermore, the active components in processed rice bran promote health; indeed, the processing itself adds value to the rice bran $[18,19]$. Such treated rice bran may protect against metabolic syndrome by attenuating hypertension, dyslipidemia and insulin resistance; it is a candidate functional food because it prevents oxidative stress in rat and mouse models [20-23]. To create a more applicable and functional bran, several fermentation processes have been used to enhance its nutritional value. Rice bran fermented using Saccharomyces cerevisiae has anti-stress and anti-fatigue effects. Furthermore, the polysaccharide extracts of rice bran fermented using Lentinus edodes showed an anti-cancer effect and they prevented defective immune responses; the water extracts of the same fermented rice bran had an anti-photoaging effect [24, 25]. Moreover, brown rice fermented using Aspergillus oryzae has a suppressive effect on dextran sulfate sodium-induced ulcerative colitis and it inhibits inflammation-mediated cell infiltration [26, 27]. Rice bran extract fermented using Lactobacillus plantarum improves functional recovery and reduces cognitive impairment after ischemic brain injury in a rat model [28, 29]. Fermentation using different microbes can increase the levels of bioactive compounds as well as the availability of functional food. For instance, fermentation using Rhizopus oryzae increases the protein content of rice bran (43\%); it also increases the levels of phenolic compounds, which have high antioxidant activity, by breaking down lignin in the substrate cell wall [30].

\subsection{Compositional improvement as functional bran}

Rice bran is processed to inactivate lipases and other nutritional inhibitors such as field fungi, bacteria and insects, to reduce their toxicity without damage to the protein quality of rice bran. The rice bran must be stabilized using suitable techniques while bran layers are removed from the endosperm during milling. Specifically, to achieve proper stabilization, each individual bran particle must have the same moisture content, depending on the time and temperature. Furthermore, to inactivate the enzymes in the rice bran that are responsible for rancidity, different stabilization methods are used. Among these, microwave energy offers an alternative energy source for stabilization [30-32]. Next, stabilization fractionation is performed. This is an important step in industrial processing; it involves the conversion of rice bran into various parts that contain more desirable than undesirable components. Subsequently, the different 
fractions are centrifuged to separate the insoluble fiber fraction - called rice bran fiber-from the aqueous dispersible fraction - called rice bran soluble. The mixture of both insoluble and soluble extracts is called rice bran balance. Using different technologies, the bran is fully stabilized and the oil is removed. The resultant food-grade, defatted rice bran is temporarily stored in food grade silos until it can be used in edible applications. Bleaching of the edible oil typically leaves minor flavor and odor compounds that must be removed by steam distillation before the oil is used. Steam distillation is the final step in the processing of edible oil, whereby any off-flavor and residual free fatty acids left in the oil are removed.

We produced two types of rice bran fraction: Driselase ${ }^{\circledR}$ fraction (DF) and ethanol fraction (EF). To process the rice bran, $500 \mathrm{~g}$ bran was agitated in $1.0 \mathrm{~L}$ of $70 \%$ ethanol for $2 \mathrm{~h}$; this yielded two fractions: the solid and filtered fractions. The DF was derived from the solid fraction. Driselase $^{\circledast}$ is a commercial plant cell wall-degrading enzyme mixture containing cellulase, xylanase and laminarinase; however, it is esterase free. The solid fraction of rice bran was dried at room temperature and then suspended in $10 \mathrm{mM}$ acetate buffer $(500 \mathrm{~mL})$ containing Driselase $(0.2 \mathrm{mg} / \mathrm{L})$ from Basidiomycetes spp. The bran was treated in this manner overnight at $37^{\circ} \mathrm{C}$; the suspension was then filtered and finally lyophilized. As a result, Driselase-treated rice bran had increased quantities of bioactive components that improve glucose and lipid metabolism in the SHRSPs - a genetic animal model of metabolic syndrome [33, 34].

\section{Extraction, isolation and identification of the active components in rice bran}

Different conventional methods are used to extract the bioactive compounds from plant materials. Of these, solvent, supercritical fluid, microwave-assisted and ultrasonic-assisted extraction are notable. Microwave-assisted extraction and ultrasound-assisted methods are used to detect antioxidant and anticancer bioactive components in the plant extracts [35, 36]. Imsanguan et al. described conventional solvent extraction, with different modifications at different temperatures $\left(32-60^{\circ} \mathrm{C}\right)$, using $100 \mathrm{ml}$ hexane at a rotating speed of $200 \mathrm{rpm}$ for $24 \mathrm{~h}$ to extract $\gamma$-oryzanol from rice bran [37]. However, this conventional technique does not fully remove toxic solvent residues from the final product; for this reason, Herrero et al. used the prominent technique of supercritical fluid extraction, which offers better extraction and purification of bioactive compounds [38]. Zigoneanu et al. described antioxidant extraction from rice bran oil using microwave-assisted extraction, which uses electromagnetic radiation in the range of $0.3-300 \mathrm{GHz}$ [39].

We developed the DF method to identify active components in the rice bran. As already described, the DF was derived from the solid fraction and chromatographed onto a silica gel column. One fraction derived from the methanol eluate was further fractionated using an octadecylsilane (ODS) column. The active fraction was obtained from the methanol/water (20$70 \%$ ) eluate and separated by high-performance liquid chromatography (HPLC) using an ODS column. The BP-lowering activity of each fraction was examined using a single oral administration to male, 14-week old SHRSPs; we found that gavage of a certain fraction at $40 \mathrm{mg} / \mathrm{kg}$ 
body weight decreased BP significantly 1, 2, 4 and $6 \mathrm{~h}$ after administration. The chemical structure of this fraction was determined using fast atom-bombardmentmass spectrometry, as well as NMR analyses; we then identified adenosine as the active compound [4].

$\gamma$-Oryzanol was initially acknowledged as a single component when it was extracted from rice bran oil. Subsequently, 10 fractions were isolated using reverse-phase HPLC and their structures were determined using gas chromatography-mass spectrometry. Cycloartenyl ferulate, 24-methylenecycloartanyl ferulate and campesteryl ferulate were identified as the major components of $\gamma$-oryzanol [40-42].

Phenolic compounds were identified in the rice bran using sequential fractionation and subfractionation using Sephadex LH-20 chromatography with $40 \%$ acetone. The total phenolic content was highest in the subfraction portion and the major phenolic acid was identified as FA $(178.3 \mu \mathrm{g} / \mathrm{mg})$ using HPLC and liquid chromatography-electrospray ionization-tandem mass spectrometry analyses $[43,44]$. The chemical structure of the active components of rice bran is illustrated in Figure 1.

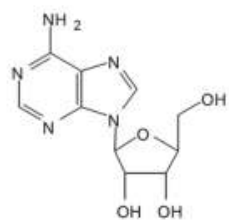

Adenosine

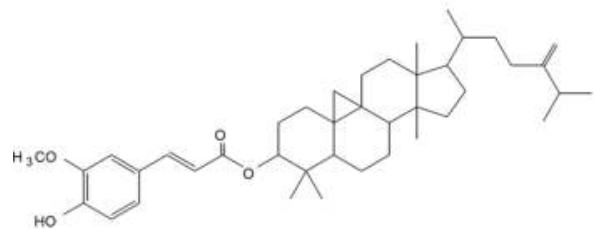

24-Methylenecycloartanyl ferulate

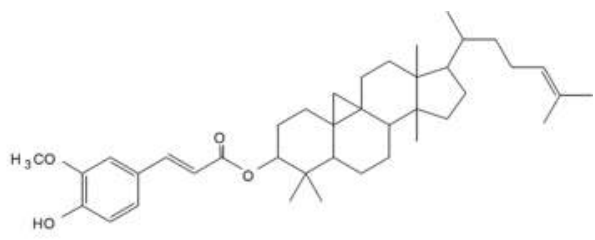

Cycloartenyl ferulate

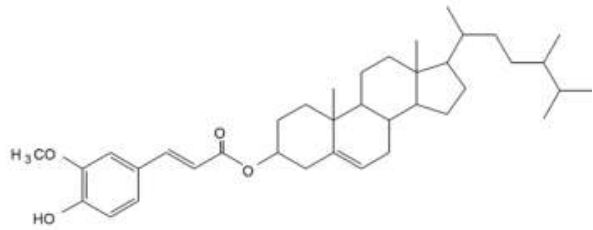

Campesteryl ferulate

Figure 1. Chemical structure of bioactive components of rice bran.

\section{Role of bioactive components}

\subsection{Hypertensive aspects}

The following factors increase the risk of diet-related disorders such as obesity, cancer and cardiovascular disease (CVD): consumption of fewer plant-based foods, changing dietary 
patterns, increased consumption of Westernized food and socioeconomic conditions. High BP, one manifestation of CVD, continues to be a major cause of morbidity and death and one public health strategy is dietary management of high BP. Studies have shown that a 5-mm Hg decrease in $\mathrm{BP}$ is related to a $16 \%$ decrease in CVD [45]. The risk factors for CVD are higher plasma cholesterol levels, lower high-density lipoprotein (HDL) levels and higher low-density lipoprotein (LDL) levels. Several bioactive compounds from rice bran that have been identified and used may reduce the risk of CVD. For instance, angiotensin-converting enzyme (ACE) inhibitors reduce BP via the renin-angiotensin system and FA has plasma ACE-inhibitory activity. In this regard, Ardiansyah et al. showed that food supplementation using FA reduces high BP by inhibiting plasma ACE activity [5]. Later, the novel compound adenosine, isolated from the DF fraction, was also found to have BP-lowering activity. Specifically, single-dose or long-term orally administered adenosine may reduce BP in the spontaneous hypertension of the SHRSP model [4]. Administered adenosine increases plasma nitric oxide levels, which in turn increase vasodilation. Adenosine also causes potent vasodilation by activating adenosine receptors (A2) on vascular smooth muscle; moreover, it stimulates $\mathrm{K}+\mathrm{ATP}$ channels, resulting in the hyperpolarization of smooth muscle [4].

The risk of CVD is elevated in conditions of oxidative stress. Urinary 8-hydroxydeoxyguanosine $(8-\mathrm{OHdG})$ serves as a sensitive biomarker of oxidative stress resulting in genetic damage. FA significantly reduces urinary 8-OHdG levels; thus, it can reduce CVD risk factors $[4,5]$.

Diets containing cholesterol-lowering phytochemicals and antioxidants can prevent the progression of atherosclerotic lesions. Experiments have demonstrated that $\gamma$-oryzanol possesses potent anti-atherogenic and antioxidant activity. Furthermore, in a rat model of twokidney, one-clip renovascular hypertension, Boonla et al. described the vasorelaxant and antihypertensive effects of peptides derived from rice bran protein hydrolysates [46]. Table 1 describes the anti-hypertensive roles of various bioactive components of rice bran.

\subsection{Metabolic disorder aspects}

Metabolic disorders consist of metabolism-related diseases, including hyperglycemia, hypercholesterolemia, hypertriglyceridemia and insulin resistance; they accompany type 2 diabetes mellitus, obesity and CVD. Rice bran and its various active components, prevents or ameliorates metabolic disorders. Specifically, a rice bran enzymatic extract-supplemented diet can prevent the adipose and macrophage changes associated with diet-induced obesity in mice [54]. In addition, the antihyperlipidemic effects (lower cholesterol and triglyceride levels) of $\alpha$-tocopherol have been investigated in F344 rats fed a Western diet [55]. Pigmented rice, which contains anthocyanins and proanthocyanidins concentrated in the bran layer, stimulates glucose uptake by 3T3-L1 adipocytes - a key function in glucose homeostasis. Specifically, basal glucose uptake is increased two to three fold, while mRNA levels of both GLUT1 and GLUT4 are upregulated [56]. $\gamma$-Oryzanol and FA ester with phytosterols - both of which are abundant in rice bran-prevent high-fat and high-fructose diet (HFFD)-induced metabolic syndrome [57]. In addition, only $\gamma$-oryzanol treatment is more effective than FA in significantly decreasing the liver index and hepatic triglyceride content. Decreased serum C-reactive protein and IL-6 levels and increased serum adiponectin concentration confirmed that FA and $\gamma$ - 
oryzanol can be used as dietary supplements to alleviate the deleterious effects of HFFD [57]. Adenosine, in particular, effectively mitigates metabolic syndrome in SHRSP [50]. Specifically, single-dose and long-term oral administration of adenosine improves hyperlipidemia and hyperinsulinemia; it also regulates body weight gain and food intake. Studies have shown that enhanced plasma adiponectin levels alleviate hyperinsulinemia and that dietary adenosine can elevate plasma adiponectin and increase insulin sensitivity. Adenosine administration for 3 weeks downregulates mRNA levels of glucose-6-phosphatase, a gene encoding the ratecontrolling enzyme of hepatic gluconeogenesis. Adenosine also plays an important role in regulating hepatic mRNA expression of genes involved in $\beta$-oxidation, fatty acid synthesis and AMP-activated protein kinase $[4,50]$. In conclusion, various active components of rice bran ameliorate metabolic-related diseases.

\begin{tabular}{|c|c|c|c|c|}
\hline Rice bran component & Species & Dose & Effect & Ref \\
\hline Adenosine & Rat & $\begin{array}{l}10 \mathrm{mg} / \mathrm{L} \text { drinking } \\
\text { water }\end{array}$ & $\begin{array}{l}\downarrow \text { Blood pressure } \\
\text { Blood } \downarrow \text { TC, LDL-C, TG, FFA, glucose, insulin, leptin, } \uparrow \\
\text { HDL-C, adiponectin } \\
\text { Liver } \downarrow \text { TC, TG }\end{array}$ & {$[4]$} \\
\hline Ferulic acid & Rat & $9.5 \mathrm{mg} / \mathrm{kg}$ BW & $\begin{array}{l}\downarrow \text { Blood pressure } \\
\text { Blood } \downarrow \text { TC, TG, ACE activity }\end{array}$ & {$[5]$} \\
\hline $\begin{array}{l}\text { Peptides-derived from } \\
\text { rice bran protein }\end{array}$ & Rat & 50-100 mg/kg BW & $\begin{array}{l}\downarrow \text { Blood pressure } \\
\text { Blood } \downarrow \text { ACE activity, } \uparrow \text { NO } \\
\text { Thoracic aorta } \uparrow \text { eNOS, } \downarrow \text { p } 47^{\text {phox }} \text { NADPH oxidase } \\
\text { subunit }\end{array}$ & [46] \\
\hline$\gamma$-Oryzanol & Rat & $0.5-2 \%$ diet & $\begin{array}{l}\text { Blood } \downarrow \text { TC, LDL-C, HDL-C, VLDL-C } \\
\text { Liver } \downarrow \text { cholesterol esters, TG }\end{array}$ & [47] \\
\hline$\gamma$-Oryzanol & Rat & $10 \mathrm{mg} / \mathrm{kg}$ BW/day & Blood $\downarrow$ TC, PL, TG, FFA, free cholesterol & [48] \\
\hline$\gamma$-Oryzanol & Rat & $1 \%$ diet & Blood $\downarrow$ TC, LDL-C, VLDL-C, TG, PL, $\uparrow$ HDL-C & [49] \\
\hline $\begin{array}{l}\text { Adenosine 5'- } \\
\text { monophosphate }\end{array}$ & Rat & $87.5 \mathrm{mg} / \mathrm{kg}$ diet & $\begin{array}{l}\downarrow \text { Blood pressure } \\
\text { Blood } \downarrow \text { TG, glucose, insulin, } \uparrow \text { HDL-C, adiponectin } \\
\text { Liver } \downarrow \text { TC, TG }\end{array}$ & {$[50]$} \\
\hline$\gamma$-Oryzanol & Human & $300 \mathrm{mg} /$ day & Blood $\downarrow$ TC, LDL-C, TG, lipid peroxides, $\uparrow$ HDL-C & [51] \\
\hline Tocotrienol & Human & $200 \mathrm{mg} /$ day & Blood $\downarrow$ TC, LDL-C, Apo B, platelet aggregation & {$[52]$} \\
\hline Rice bran oil & Human & 50 g/day & Blood $\downarrow$ TC, LDL-C, TG & [53] \\
\hline
\end{tabular}

ACE, angiotensin-converting enzyme; ApoB, apolipoprotein B; BW, body weight; FFA, non-esterified fatty acid; HDL-C, high density lipoprotein cholesterol; LDL-C, low density lipoprotein cholesterol; PL, phospholipid; TC, total cholesterol; TG, triglycerides; VLDL-C, very low density lipoprotein cholesterol; eNOS, endothelial nitric oxide synthase.

Table 1. Summary of bioactive components and their prospective effects on blood pressure and metabolic parameters in different species.

\subsection{Anti-cancer aspects}

Dietary factors have a significant effect on the risk of cancer. Only $5-10 \%$ of all cancer is heredity; all other incidents are directly or indirectly correlated with lifestyle and dietary habits. If dietary supplements are used appropriately, they may reduce the incidence of cancers 
in humans by as much as $30 \%[58,59]$. Phytic acid extracted from rice bran has anticancer activity against hepatocellular carcinoma (HepG2) cells, wherein apoptotic activity was evaluated by expression analysis of apoptosis-regulatory genes (i.e., p53, Bcl-2, Bax, Caspase3 and -9) [60]. Similarly, $\delta$-tocotrienol ( $\delta$-T3) is reportedly useful as an anticancer agent against human colorectal adenocarcinoma (DLD-1) cells under both normoxic and hypoxic conditions. In vivo, oral administration of rice bran tocotrienol (mainly $\gamma$-T3; $10 \mathrm{mg} / \mathrm{mouse} /$ day) significantly inhibited tumor growth in nude mice [61]. Tumor cells produce reactive oxygen species, which damage cellular integrity. Cycloartenyl ferulate, a major component of $\gamma$-oryzanol, successfully inhibits proliferation in the colorectal adenocarcinoma SW480 cell line because of its antioxidant activity [62].

\subsection{General health-promoting aspects}

Rice bran itself has health benefits, while rice bran oil and isolated active components have immune stimulatory effects. Rice bran that is rich in phytosterols, $\gamma$-oryzanol and compounds with antioxidant properties may modulate the immune system. In addition, rice bran has several generalized health-promoting characteristics. For example, rice bran supplementation enhances gut health by encouraging the growth and colonization of Lactobacillus rhamnosus and it provides effective protection against human rotavirus diarrhea in pigs by modulating gut permeability [63].

Long-term supplementation has a positive impact on survival, cognition and brain mitochondrial function, which may delay Alzheimer's disease [64]. Rice bran supplements can also be used as ergogenic supplements by body builders and athletes [65] and they may mitigate menopausal symptoms such as hot flashes, as well as bone loss in older women who suffer from osteoporosis [66]. Rice bran can be regarded as a source of plant-derived active compounds and as an alternative to expensive vitamin sources from animals. For instance, different colored rice bran has micronutrients, including a rich reserve of $\beta$-carotene, which can be converted to vitamin A [67]. Table 2 describes the role of various bioactive components of rice bran for general health.

\begin{tabular}{|c|c|c|c|c|}
\hline $\begin{array}{l}\text { Rice bran } \\
\text { component }\end{array}$ & Health aspects & Dose & Effect & Ref \\
\hline Rice bran & $\begin{array}{l}\text { HRV induced diarrhea } \\
\text { prevention in gnotobiotic pigs }\end{array}$ & $10 \%$ & $\begin{array}{l}\uparrow \text { Intestinal IFN- } \gamma \text { and total IgA } \\
\text { levels }\end{array}$ & [63] \\
\hline$\gamma$-Oryzanol & Brain aging in NMRI mice & $\begin{array}{l}4 \mathrm{~g} / \mathrm{kg} \text { diet for } 6 \\
\text { months }\end{array}$ & $\uparrow$ Mitochondrial proteins & [64] \\
\hline$\gamma$-Oryzanol & Human health growth & $500 \mathrm{mg} /$ day & $\begin{array}{l}\uparrow \text { Muscular strength (bench press } \\
\text { and squat) and vertical jump power }\end{array}$ & [65] \\
\hline$\gamma$-Oryzanol & $\begin{array}{l}\text { Postmenoposal osteoporosis in } \\
\text { rats }\end{array}$ & $\begin{array}{l}0.3 \% \text { crystalized } \\
\text { oryzanol }\end{array}$ & $\uparrow$ Estrogen, Bone mineral & [66] \\
\hline
\end{tabular}

HRV, human rota virus; IFN- $\gamma$, interferon gamma; IgA, immunoglobulin A.

Table 2. Summary of bioactive components and their prospective effect on generalized health aspects. 


\section{Conclusion}

Previously, rice bran was only used in animal feed or discarded as waste. However, now it is treated as a potential source for the preparation of nutraceuticals. In this review, the therapeutic role of rice bran itself and of its bioactive and novel components has been described briefly from different clinical points of view. We noted that rice bran has various health benefits in terms of disease prevention and that it can be used to treat humans and experimental animals with no side effects. Owing to its significant nutritive and therapeutic value, rice bran may enhance well-being and health, as well as reduce the risk of disease, providing health benefits and improving quality of life. Thus, rice bran can be considered a super food and/or functional food. However, the true potential of functional bran could be developed using new biotechnological methods.

In conclusion, there is a strong demand for the enrichment of functional bran components in different diet-based approaches that mitigate lifestyle-related disorders. Entrepreneurs should be encouraged to consider rice bran as a major source of bioactive components for the developments of super foods.

\section{Author details}

Md. Alauddina ${ }^{1}$, Jahidul Islama ${ }^{1}$, Hitoshi Shirakawaa ${ }^{1 *}$, Takuya Kosekib $^{2}$, Ardiansyahc ${ }^{3}$ and Michio Komaia ${ }^{1}$

*Address all correspondence to: shirakah@m.tohoku.ac.jp

1 Laboratory of Nutrition, Department of Science of Food Function and Health, Graduate School of Agricultural Science, Tohoku University, Sendai, Japan

2 Faculty of Agriculture, Yamagata University, Yamagata, Japan

3 Department of Food Science \& Technology, Universitas Bakrie, Jakarta, Indonesia

\section{References}

[1] Zhou Z, Robards K, Helliwell S, Blanchard C. Composition and functional properties of rice. Int. J. Food Sci. Technol. 2002;37(8):849-868.

[2] Weststrate JA, van Poppel G, Verschuren PM. Functional foods, trends and future. Br. J. Nutr. 2002;88(2):S233-S235.

[3] Roberfroid M. Functional food concept and its application to prebiotics. Dig. Liver Dis. 2002;34(2):SS105-S110. 
[4] Ardiansyah, Shirakawa H, Shimeno T, Koseki T, Shiono Y, Murayama T, et al. Adenosine, an identified active component from the Driselase-treated fraction of rice bran, is effective at improving metabolic syndrome in stroke-prone spontaneously hypertensive rats. J. Agric. Food Chem. 2009;57(6):2558-2564.

[5] Ardiansyah, Ohsaki Y, Shirakawa H, Koseki T, Komai M. Novel effects of a single administration of ferulic acid on the regulation of blood pressure and the hepatic lipid metabolic profile in stroke-prone spontaneously hypertensive rats. J. Agric. Food Chem. 2008;56(8):2825-2830.

[6] Gul K, Yousuf B, Singh AK, Singh P, Wani AA. Rice bran: nutritional values and its emerging potential for development of functional food: a review. Bioactive Carbohydr. Diet. Fibre 2015;6(1):24-30.

[7] Oliveira Mdos S, Feddern V, Kupsk L, Cipolatti EP, Badiale-Furlong E, de SouzaSoares LA. Changes in lipid, fatty acids and phospholipids composition of whole rice bran after solid-state fungal fermentation. Bioresour. Technol. 2011;102(17):83358338 .

[8] Lemos MRB, Souza-Soares LA. Rice and its byproducts in southern Brazil. Vetor: Revista de Ciencias Exatas e Engenharias 2000;10:21-36.

[9] Saunders RM. Rice bran: composition and potential food uses. Food Rev. Int. 1985;1(3): 465-495.

[10] Sugano M, Tsuji E. Rice bran oil and cholesterol metabolism. J. Nutr. 1997;127(3):521S$524 \mathrm{~S}$.

[11] Iqbal S, Bhanger MI, Anwar F. Antioxidant properties and components of some commercially available varieties of rice bran in Pakistan. Food Chem. 2005;93(2): 265-272.

[12] Yan JJ, Cho JY, Kim HS, Kim KL, Jung JS, Huh SO, et al. Protection against beta-amyloid peptide toxicity in vivo with long-term administration of ferulic acid. Br. J. Pharmacol. 2001;133(1):89-96.

[13] Garcia-Conesa MT, Wilson PD, Plumb GW, Ralph J, Williamson G. Antioxidant properties of 4,4'-dihydroxy-3,3'-dimethoxy- $\beta, \beta$ '-bicinnamic acid (8,8-diferulic acid, noncyclic form). J. Sci. Food Agric. 1999;79(3):379-384.

[14] Suzuki A, Kagawa D, Fujii A, Ochiai R, Tokimitsu I, Saito I. Short and long term effect of ferulic acid on blood pressure in spontaneously hypertensive rats. Am. J. Hypertens. 2002;15(4 Pt 1):351-357.

[15] Boonloh K, Kukongviriyapan V, Kongyingyoes B, Kukongviriyapan U, Thawornchinsombut S, Pannangpetch P. Rice bran protein hydrolysates improve insulin resistance and decrease pro-inflammatory cytokine gene expression in rats fed a high carbohydrate-high fat diet. Nutrients 2015;7(8):6313-6329. 
[16] Kahlon TS, Chow FI, Sayre RN, Betschart AA. Cholesterol-lowering in hamsters fed rice bran at various levels, defatted rice bran and rice bran oil. J. Nutr. 1992;122(3):513519.

[17] Nicolosi RJ, Ausman LM, Hegsted DM. Rice bran oil lowers serum total and low density lipoprotein cholesterol and apo B levels in nonhuman primates. Atherosclerosis 1991;88(2-3):133-142.

[18] Palou M, Sánchez J, García-Carrizo F, Palou A, Picó C. Pectin supplementation in rats mitigates age-related impairment in insulin and leptin sensitivity independently of reducing food intake. Mol. Nutr. Food Res. 2015;59(10):2022-2033.

[19] Wang O, Liu J, Cheng Q, Guo X, Wang Y, Zhao L, et al. Effects of ferulic acid and $\gamma$ oryzanol on high-fat and high-fructose diet-induced metabolic syndrome in rats. PLoS One 2015;10(2):e0118135.

[20] Candiracci M, Justo ML, Castaño A, Rodriguez-Rodriguez R, Herrera MD. Rice bran enzymatic extract-supplemented diets modulate adipose tissue inflammation markers in Zucker rats. Nutrition 2014;30(4):466-472.

[21] Justo ML, Candiracci M, Dantas AP, de Sotomayor MA, Parrado J, Vila E, et al. Rice bran enzymatic extract restores endothelial function and vascular contractility in obese rats by reducing vascular inflammation and oxidative stress. J. Nutr. Biochem. 2013;24(8):1453-1461.

[22] Justo ML, Rodriguez-Rodriguez R, Claro CM, Alvarez de Sotomayor M, Parrado J, Herrera MD. Water-soluble rice bran enzymatic extract attenuates dyslipidemia, hypertension and insulin resistance in obese Zucker rats. Eur. J. Nutr. 2012;52(2):789_ 797.

[23] Ryan EP, Heuberger AL, Weir TL, Barnett B, Broeckling CD, Prenni JE. Rice bran fermented with saccharomyces boulardii generates novel metabolite profiles with bioactivity. J. Agric. Food Chem. 2011;59(5):1862-1870.

[24] Kim KM, Yu KW, Kang DH, Suh HJ. Anti-stress and anti-fatigue effect of fermented rice bran. Phytother. Res. 2002;16(7):700-702.

[25] Kim HY, Kim JH, Yang SB, Hong SG, Lee SA, Hwang SJ, et al. A polysaccharide extracted from rice bran fermented with Lentinus edodes enhances natural killer cell activity and exhibits anticancer effects. J. Med. Food. 2007;10(1):25-31.

[26] Jung EH, Kim SR, Hwang IK, Ha TY. Hypoglycemic effects of a phenolic acid fraction of rice bran and ferulic acid in C57BL/KsJ-db/db mice. J. Agric. Food Chem. 2007;55(24): 9800-9804.

[27] Kataoka K, Ogasa S, Kuwahara T, Bando Y, Hagiwara M, Arimochi H, et al. Inhibitory effects of fermented brown rice on induction of acute colitis by dextran sulfate sodium in rats. Dig. Dis. Sci. 2008;53(6):1601-1608. 
[28] Hong JH, Kim JY, Baek SE, Ingkasupart P, Park HJ, Kang SG. Effects of rice bran extracts fermented with Lactobacillus plantarum on neuroprotection and cognitive improvement in a rat model of ischemic brain injury. Biomed. Sci. Lett. 2015;21:92102.

[29] Baek SE, Kim JY, Song WT, Lee SH, Hong JH, Lee CK, et al. Neuroprotective effect of rice bran extract supplemented with ferulic acid in the rat model of ischemic brain injury. Anim. Cells Syst. 2014;18(2):93-100.

[30] Kupski L, Cipolatti E, da Rocha M, dos Santos Oliveira M, de Almeida Souza-Soares L, Badiale-Furlong E. Solid-state fermentation for the enrichment and extraction of proteins and antioxidant compounds in rice bran by Rhizopus oryzae. Braz. Arch. Biol. Technol. 2012;55(6):937-942.

[31] Wataniyakul P, Pavasant P, Goto M, Shotipruk A. Microwave pretreatment of defatted rice bran for enhanced recovery of total phenolic compounds extracted by subcritical water. Bioresour. Technol. 2012;124:18-22.

[32] dos Santos Conceição Faria SA, Bassinello PZ, de Vuono Camargo Penteadol M. Nutritional composition of rice bran submitted to different stabilization procedures. Braz. J. Pharm. Sci. 2012;48(4):651-657.

[33] Ardiansyah, Shirakawa H, Koseki T, Ohinata K, Hashizume K, Komai M. Rice bran fractions improve blood pressure, lipid profile and glucose metabolism in stroke-prone spontaneously hypertensive rats. J. Agric. Food Chem. 2006;54(5):1914-1920.

[34] Ardiansyah, Shirakawa H, Koseki T, Hashizume K, Komai M. The Driselase-treated fraction of rice bran is a more effective dietary factor to improve hypertension, glucose and lipid metabolism in stroke-prone spontaneously hypertensive rats compared to ferulic acid. Br. J. Nutr. 2007;97(1):67-76.

[35] Proestos C, Komaitis M. Application of microwave-assisted extraction to the fast extraction of plant phenolic compounds. LWT-Food Sci. Technol. 2008;41(4):652-659.

[36] Ghasemzadeh A, Jaafar HZ, Karimi E, Rahmat A. Optimization of ultrasound-assisted extraction of flavonoid compounds and their pharmaceutical activity from curry leaf (Murraya koenigii L.) using response surface methodology. BMC Complement. Altern. Med. 2014;14:318.

[37] Imsanguan P, Roaysubtawee A, Borirak R, Pongamphai S, Douglas S, Douglas PL. Extraction of $\alpha$-tocopherol and $\gamma$-oryzanol from rice bran. LWT-Food Sci. Technol. 2007;41(8):1417-1424.

[38] Herrero M, Mendiola JA, Cifuentes A, Ibáñez E. Supercritical fluid extraction: recent advances and applications. J. Chromatogr. A 2010;1217(16):2495-2511.

[39] Zigoneanu IG, Williams L, Xu Z, Sabliov CM. Determination of antioxidant components in rice bran oil extracted by microwave-assisted method. Bioresour. Technol. 2008;99(11):4940-4948. 
[40] Nicolosi RJ, Rogers EJ, Ausman LM, Orthoefer FT. Rice bran oil and its health benefits. In: Rice Science and Technology. New York Inc.: Marshall Dekker; 1994.

[41] Duve JK, White PJ. Extraction and identification of antioxidants in oats. J. Am. Oil Chem. Soc. 1991;68(6):365-370.

[42] Xu Z, Godber JS. Purification and identification of components of $\gamma$-oryzanol in rice bran oil. J. Agric. Food Chem. 1999;47(7):2724-2728.

[43] Brand-Williams W, Cuvelier ME, Berset C. Use of a free radical method to evaluate antioxidant activity. LWT -Food Sci. Technol. 1995;28(1):25-30.

[44] Rice-Evans CA, Miller NJ, Paganga G. Structure-antioxidant activity relationships of flavonoids and phenolic acids. Free Radic. Biol. Med. 1996;20(7):933-956.

[45] FitzGerald RJ, Murray BA, Walsh DJ. Hypotensive peptides from milk proteins. J. Nutr. 2004;134(4):980S-988S.

[46] Boonla O, Kukongviriyapan U, Pakdeechote P, Kukongviriyapan V, Pannangpetch P, Thawornchinsombut S. Peptides-derived from Thai rice bran improves endothelial function in 2K-1C renovascular hypertensive rats. Nutrients. 2015;7(7): 5783-5799.

[47] Shinomiya M, Morisaki N, Matsuoka N, Izumi S, Saito Y, Kumagai A, et al. Effects of gamma-oryzanol on lipid metabolism in rats fed high cholesterol diet. Tohoku J. Exp. Med. 1983;141(2):191-197.

[48] Sakamoto K, Tabata T, Shirasaki K, Inagaki T, Nakayama S. Effects of gamma-oryzanol and cycloartenol ferulic acid ester on cholesterol diet induced hyperlipidemia in rats. Jpn. J. Pharmacol. 1987;45(4):559-565.

[49] Seetharamaiah GS, Chandrasekhara N. Effect of oryzanol on fructose induced hypertriglyceridemia in rats. Indian J. Med. Res. 1988;88:278-281.

[50] Ardiansyah, Shirakawa H, Koseki T, Hiwatashi K, Takahasi S, Akiyama Y, et al. Novel effect of adenosine 5'-monophosphate on ameliorating hypertension and the metabolism of lipids and glucose in stroke-prone spontaneously hypertensive rats. J. Agric. Food Chem. 2011;59(24):13238-13245.

[51] Ishihara M, Ito $Y$, Nakakita T, Maehama T, Hieda S, Yamamoto K, et al. Clinical effect of gamma-oryzanol on climacteric disturbance -on serum lipid peroxides. Nippon Sanka Fujinka Gakkai Zasshi 1982;34(2):243-251.

[52] Raghuram TC, Rao UB, Rukmini C. Studies on hypolipidemic effects of dietary rice bran oil in human subjects. Nutr. Rep. Int. 1989;35:889-895.

[53] Qureshi AA, Bradlow BA, Salser WA, Brace LD. Novel tocotrienols of rice bran modulate cardiovascular disease risk parameters of hypercholesterolemic humans. J. Nutr. Biochem. 1997;8(5):290-298. 
[54] Justo ML, Claro C, Zeyda M, Stulnig TM, Herrera MD, Rodríguez-Rodríguez R. Rice bran prevents high-fat diet-induced inflammation and macrophage content in adipose tissue. Eur. J. Nutr. 2015;55(6):2011-2019.

[55] Shibata A, Kawakami Y, Kimura T, Miyazawa T, Nakagawa K. $\alpha$-Tocopherol attenuates the triglyceride- and cholesterol-lowering effects of rice bran tocotrienol in rats fed a western diet. J. Agric. Food Chem. 2016;64(26):5361-5366.

[56] Boue SM, Daigle KW, Chen MH, Cao H, Heiman ML. Antidiabetic potential of purple and red rice (Oryza sativa L.) bran extracts. J. Agric. Food Chem. 2016;64(26): 5345-5353.

[57] Wang O, Liu J, Cheng Q, Guo X, Wang Y, Zhao L, et al. Effects of ferulic acid and $\gamma$ oryzanol on high-fat and high-fructose diet-induced metabolic syndrome in rats. PLoS One 2015;10(2):e0118135.

[58] Anand P, Kunnumakkara AB, Sundaram C, Harikumar KB, Tharakan ST, Lai OS, et al. Cancer is a preventable disease that requires major lifestyle changes. Pharm. Res. 2008;25(9):2097-2116.

[59] Willett WC. Balancing life-style and genomics research for disease prevention. Science. 2002;296:695-698.

[60] Al-Fatlawi AA, Al-Fatlawi AA, Irshad M, Zafaryab M, Rizvi MM, Ahmad A. Rice bran phytic acid induced apoptosis through regulation of Bcl-2/Bax and p53 genes in HepG2 human hepatocellular carcinoma cells. Asian Pac. J. Cancer Prev. 2014;15(8): 3731-3736.

[61] Shibata A, Nakagawa K, Tsuduki T, Miyazawa T. $\delta$-Tocotrienol treatment is more effective against hypoxic tumor cells than normoxic cells: potential implications for cancer therapy. J. Nutr. Biochem. 2015;26(8):832-840.

[62] Kong CK, Lam WS, Chiu LC, Ooi VE, Sun SS, Wong YS. A rice bran polyphenol, cycloartenyl ferulate, elicits apoptosis in human colorectal adenocarcinoma SW480 and sensitizes metastatic SW620 cells to TRAIL-induced apoptosis. Biochem. Pharmacol. 2009;77(9):1487-1496.

[63] Yang X, Twitchell E, Li G, Wen K, Weiss M, Kocher J, et al. High protective efficacy of rice bran against human rotavirus diarrhea via enhancing probiotic growth, gut barrier function and innate immunity. Sci. Rep. 2015;5:15004.

[64] Hagl S, Asseburg H, Heinrich M, Sus N, Blumrich EM, Dringen R, et al. Effects of long-term rice bran extract supplementation on survival, cognition and brain mitochondrial function in aged MNRI mice. Neuromolecular Med. 2016;18(3):347363.

[65] Fry AC, Bonner E, Lewis DL, Johnson RL, Stone MH, Kraemer WJ. The effects of gamma-oryzanol supplementation during resistance exercise training. Int. J. Sport Nutr. 1997;7(4):318-329. 
[66] Colona HC. The effects of oryzanol on bone mineral density in ovariectomized, retired breeder rats [thesis]. Louisiana State University: 2002.

[67] Nagao A. Oxidative conversion of carotenoids to retinoids and other products. J. Nutr. 2004;134(1):237S-240S. 
